\title{
REJUVENATING THE MARKETING MIX THROUGH NEUROMARKETING TO CULTIVATE THE GREEN CONSUMER
}

\author{
Salmi Mohd Isa ${ }^{1 *}$, Aida Azlina Mansor² \\ $1^{*}$ Graduate School of Business, Universiti Sains Malaysia. \\ 2 Department of Entrepreneurship \& Marketing Studies, Faculty of Business \& Management, Universiti Teknologi MARA.
}

ABSTRACT - In the 21 st century, the growth of environmentally friendly products caught attention primarily from both consumers and companies. One of the most interesting trends is consumers' growing environmental conscience and social impacts of the products they buy. The preference for green products is clearly increasing. Consumers want to act green, but they expect businesses to lead the way. However, many companies experienced problems to understand the consumers' decision-making process. Consumers are equally confused when they do not quite understand how to act on their greener impulses. Many attempts to label green products are meaningless at best and mystifying at worst. In other words, companies must move customers through the entire purchasing process-from being aware of eco-friendly products, to considering their pros and cons, to paying for the products. Due to this issue, a significant advancement of neuroscience has resulted in the emergence of neuromarketing, which provides a better understanding of how subconscious minds react in everyday situations, especially in marketing activities. This new concept brings powerful insights and techniques into marketing research especially on consumers' behaviour analysis. In this view, this study looks at the growing field of neuromarketing and aims to explore consumers' subconscious minds by examining the effectiveness of marketing mix on consumers' decision-making process. This study employed Event-related Potential (ERP) and Eye Tracking (ET) to examine consumers' subconscious minds towards the main component of the marketing mix during the decision-making process. A laboratory experiment employed twenty-two volunteers to take part in the study. The results revealed that price and promotion elements are the key attributes which consumers consider in purchasing green product. Thus, neuromarketing can reconfigure and improve conventional theories of marketing. This evidence offers a new marketing opportunity for marketers to improvise their marketing strategy and thus, increase their sales growth.
ARTICLE HISTORY

Received:29-11-2019

Accepted:4-3-2020

\section{KEYWORDS}

Neuromarketing,

marketing mix,

Event-related Potential

(ERP),

eye tracking (ET),

subconscious decision

making,

green consumerism

\section{INTRODUCTION}

Neuromarketing is an emerging interdisciplinary field at the interface between neuroscience, psychology, and marketing. These new concepts provide a powerful understanding and scientific approach to marketing research, especially on consumers' behaviour. In this 21 st century, the growth of green products caught much attention, primarily from both consumers and companies. As consumers are becoming more and more concerned about the environment, marketers have begun to change how they produce their products and implement a new marketing strategy. Looking at a myriad of issues in the marketing field lately, it is now a trend for marketers to adopt the concept of green marketing in order to support consumers' green purchase behaviour.

In retrospect, Abdul Wahid, Rahbar, and Tan (2011) found that the practice of purchasing green products is still low in Malaysia and consumers' perceptions regarding environmentally friendly products are not enhanced compared to conventional products. This is supported by Do Paço, Alves, Shiel, and Filho (2013), who mentioned that even though consumers express real concern for the environment, their attitudes are not always translated into their purchasing behaviour. Therefore, it is crucial to recognise consumers' decision-making behaviour from another perspective, which is from consumers' subconscious mind. In order to understand how subconscious minds work, exploring consumers' brains and activity helps to understand the concept behind the decision-making process.

Therefore, there is a need for an investigation to understand consumers' decision-making process from subconscious perspectives in order to produce an effective marketing mix strategy. Processing of information at the subconscious level performs a great role in consumers' decision making (Agarwal \& Dutta, 2015). Thus, there is a potential to discover a consumers' subconscious processes which will determine the consumers' decision-making process and it will then reveal the hidden information about the consumers' behaviour, which are not obtainable by traditional marketing methods (Colaferro \& Crescitelli, 2014). This study aims to gain a better understanding of the consumers' subconscious minds in making decisions to purchase green products. With the help of neuroscience tools, it is important to have some knowledge of the consumers' subconscious minds, in such a way that may appropriately assist the marketers to regulate and improve their marketing mix strategies (McDowell \& Dick, 2013). 


\section{LITERATURE REVIEW}

\section{Neuromarketing}

Neuromarketing or consumer neuroscience denotes a new interdisciplinary field of study. It is known as an extension of neuroscience and marketing discipline (Lee, Broderick, \& Chamberlain, 2007). The integration between these disciplines; neuroscience and marketing opened the path of neuromarketing. Thus, there has been an increase in interest and attention in the neuromarketing study among marketing scholars and experts. This is mainly due to the fact that neuromarketing has provided capabilities to discover and to predict consumer behaviour better. Neuromarketing is important for tackling the issues on the consumers' subconscious mind such as emotion, preference, or memory (Hammou, Galib \& Melloul, 2013), where it goes beyond the traditional marketing methods. Therefore, the existence of neuromarketing is to quantify, explain, and exploit the unseen subconscious level of consumers in the decision-making process. With the help of neuroscience, it is important to have knowledge of the consumers' subconscious mind in which may appropriately assist companies to adjust their marketing strategies (McDowell \& Dick, 2013). Neuromarketing may go on to discover new benefits that might trump the traditional marketing research tools and can be used as the foundation for a more effective marketing campaign (Mansor \& Isa, 2018).

There are growing numbers of research focusing on using eye-tracking to study human behaviour. Eye-tracking (ET) according to Santos et al. (2015), is a tool for the analysis of visual attention and it seeks to associate visual attention with the rational and emotional responses of consumers. Eye-tracking is part of neuroscience techniques, which measure the respondent's responses indirectly rather than directly. Huang and Kuo (2011) reported a study that confirmed eye tracking provides more accurate information than self-report and can be useful in advertisements development and assessment, concept testing, logo and package design, online usability, and micro-site development or in-store marketing. meanwhile, Santos et al., (2015) stated that the results of eye-tracking research are practical in marketing applications, such as brand equity, segmentation, new product development, pricing decisions, place decisions, promotion decisions, and social marketing studies. On the other hand, Event-related Potential (ERP) are techniques that provide a temporal resolution of milliseconds, which reflect the electrical response of the brain. The third positive wave of the ERP was named P3 or P300 and is the main ability of the brain to process incoming information. Therefore, for many years, P300 components have been studied in marketing topics related to attitudes and preferences, information-based, and decision making (Lin et al., 2018).

\section{Marketing mix: The 4Ps with neuromarketing}

According to Kolar (2014), neuromarketing can be used to obtain valuable information on consumers' preferences regarding products and services by investigating the marketing mix. The marketing mix is shortened to the original four elements: (i) product, (ii) price, (iii) place, and (iv) promotion-the 4Ps. Aaker (1996) suggested that brand equity measures should reflect the asset value of the brand and focus on sustainable marketing tactics that can not be easily copied. Meanwhile, Khan (2014) suggested that the marketing mix is the most fundamental concept and many organisations use the 4Ps to create a desired response in the targeted market. Moreover, the 4Ps are the important attributes that consumers consider when making a green purchase decision (Gan et al., 2008). These attributes can transform consumers' attitudes to greener consumption (Pickett-Baker \& Ozaki, 2008). If business organisations missed the trend of the scientific approach in developing a marketing strategy, their business will eventually experience stagnation. The stagnation is mainly caused by the inability of marketers to identify what is the actual demand of customers. The traditional marketing approach only tells whether the marketing strategy works or fails based on the return of investment, but never effectively allowed marketers to understand why it fails (Sadedil, Bozkurt, Uraltas \& Tas 2016).

Neuroimaging techniques are used to test any hypothesis and the influence of marketing stimuli on the consumers' brain. According to Sowndhararajan, Kim, Deepa, Park, and Kim (2018), P300 amplitude has a positive effect on the memory capabilities of healthy people, and P300 amplitude decreases are linked to decreases in intelligence activation and cognitive impairment. This is because it is assumed that variations in P300 amplitude reflect the degree to which this information is processed. Thus, the lower P300 amplitude in descriptive conditions revealed that participants used higher memory loads when making decisions (Wang, Zheng, Huang \& Sun, 2015). Therefore, marketers must always keep in mind that green marketing must accompany the attributes of 4Ps in order to earn attention from consumers. Moreover, Isa, Kelly, and Kiumarsi (2020) revealed that price and promotion have effects on brand switching. Their study also showed that brand will affects the connections between product, price, and brand switching. Therefore, if a company cannot grasp what type of product and service, or values that customers pursue, it is inevitable that the company will keep doing the same thing in the future, without branching out effort in other areas. If a company develops the right mix in its marketing strategy, the product that it is selling will be successful and strong (Heding, Knudtzen \& Bjerre, 2009).

\section{Consumer decision making and green products}

Decision-making is a process that makes the final choice of whether the consumer will buy the products. Therefore, understanding and considering the behaviour of consumers and the basic causes behind their purchasing decisions are important success factors (Hammou et al., 2013). For example, price plays an important role in the consumer's decision to buy green products. The main purpose is to bring the products to the target market and to offer them to the needs and wants of specific groups and to offer them at the right time for groups of consumers who are willing to pay. Traditional product features like price, quality, and brand are the most important attributes that consumers consider when making 
purchase decisions (Gan et al., 2008). As consumers are increasingly concerned about the environment, marketers have begun to change their manufacturing aspects and implement a new marketing strategy.

As a result, marketers started to structure their marketing systems so that green consumers can pay attention. Price is the factor in the green marketing mix, which is the most imperative and critical. Price is an important element when deciding to buy green products. This is because not all consumers are willing to pay a higher price for green products (Gan et al., 2008; Barbarossa \& Pastore, 2015). This is because consumers are very sensitive to price changes and it easily affects consumers purchasing decisions. However, consumers are willing to pay more for environment-friendly products (Boztepe, 2012). Environmentally conscious consumers are willing to purchase green products and pay a higher price. In another study by Ying-Ching and Chang (2012), and Suki (2013) found that even if the green products may be less effective in product performance compared to regular products, consumers were willing to pay a high price for said products.

There is evidence to suggest that consumers are price and quality sensitive when it comes to green purchase behaviour. In a study conducted by Banyte, Brazioniene, and Gadeikiene (2010), they found that if the green product is low in price, consumers do not trust the green products. This is because to them, a low price of green products shows that said products are not of good quality. This is because consumers consider both the price and quality of recycled products altogether. Price, place, and promotion of green products were also found to be the factors that influence the purchase of green products. However, consumers' perceptions of price and availability may vary by changing other barriers such as green product displacement inside the store and in-store communication (Barbarossa \& Pastore, 2015).

\section{METHODOLOGY}

Laboratory experiments were carried out in this study to capture consumers' decision-making processes. In this study, the population comprised of 22 healthy adult consumers who were volunteers from both genders, male and female. The study required that the respondents should be of age 18 years old and above. The respondents were volunteering to participate in the study. Furthermore, they were familiar with the purchasing of products and they were also empowered in their decisions for choosing the right products between many available choices. The procedure of the study was approved by the Human Ethical Committee of Universiti Sains Malaysia (USM) with the reference number USM/JePeM/16080255.

Each of the products is separated into four (4) main marketing categories (product, price, place, and promotion). The session began with a fixation (+) mark and was followed by a stimulus. The stimulus was presented in categories and random orders. The stimuli were presented by E-Prime software version 2.8 connected with 128 channels of HydroCell Geodesic Sensor Net (GSN). Standard pictures used in this study were collected from the internet which is open-source and there is no watermark of copyright restrictions. The main reason to choose the products is that it is a product that consumers frequently buy and use immediately, which are mainly sold in retail stores and have a short useful life cycle.

\section{Event-related potential (ERP) procedure}

For the ERP study, 128 sensor nets were used. Each subject was asked to take a decision task after the preparation and application processes of the net. The respondents were also asked to sit about $100 \mathrm{~cm}$ from the computer screen. The amplitudes and latencies of P300 components were measured. Stimuli were presented through E-prime software. The frequent (standard) is non-green product and rare (target) is a green product and both products were tested in random order. For the procedure of the visual experiment, the design of each session is shown in Figure 1. Respondents were given the task of responding to the messages for each of the two alternative products and were asked to select one to purchase: either YES or NO by pressing the answer button. Firstly, a black screen was shown to the participant (3 seconds). Secondly, a white cross in the center of the screen was given to inform the subject that visual stimulus would be shown ( 4 seconds). Thirdly, the pictures were shown to the subject (4 pictures x 10 seconds/clip=40 seconds). For each stimulus, the visual between green and the non-green product was displayed randomly. Lastly, a black screen was presented to the participant again ( 3 seconds). In summary, each session usually took 40 to 60 minutes to complete.

\begin{tabular}{|c|c|c|c|c|c|c|}
\hline Black screen & "+" cross & Picture 1 & Picture 2 & Picture 3 & Picture 4 & Black screen \\
$3 \mathrm{~s}$ & $4 \mathrm{~s}$ & $10 \mathrm{~s}$ & $10 \mathrm{~s}$ & $10 \mathrm{~s}$ & $10 \mathrm{~s}$ & $3 \mathrm{~s}$ \\
\hline
\end{tabular}

Figure 1. The procedure of visual stimuli experiment

\section{Eye-tracking (ET) procedure}

Respondents were sitting in a comfortable chair and asked to sit behind the screen. SMI Eye Tracking Glasses 2 Wireless were designed to capture a subject's natural gaze behaviour in real-time. The eye tracker was attached to a 15inch screen placed from the respondents between 23 and 32 inches. Each subject was asked to do a decision task after the calibration process. Respondents were asked to look at the green and non-green body wash and make their choice. For the eye-tracking experiment, the researcher developed images of two types of products: green and non-green body wash products and manipulated the information on the product which are place, price, and promotion. For this study, the researcher chose a body wash as an experiment stimulus. Figure 2 illustrates the stimuli for the eye-tracking experiment. The body wash was chosen because the respondents had a moderate level of product engagement and the product was consumed by male and female respondents. Respondents were asked to look at each picture to examine the products. In order to set up an eye tracker to the system, the correct position started with simple calibration. Calibration is important 
before starting the experiment because it establishes the relationship between the position of the eye and the gaze point. After the calibration process was done, the stimuli of the study were then ready to launch, and the respondent was asked to do a decision task. For the decision task, respondents were asked to purchase a body wash of their choice and progressed with their choice.

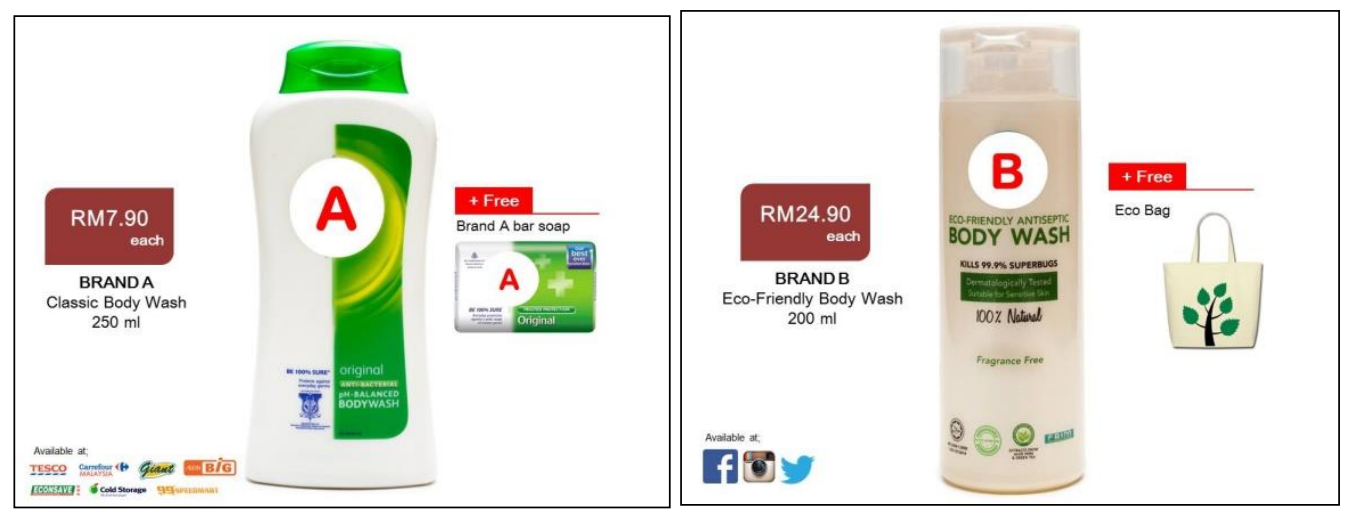

Figure 2. Stimuli for eye-tracking experiment

\section{Data analysis}

The output from ERP waveform analysis statistical extraction containing amplitude and latency by using Net-Station software of all electrodes was transferred to Graphpad Prism 8. Means and standard deviations were used to determine the level of amplitude and latency between green and non-green products. An independent t-test was used to determine the mean reaction time difference for green and non-green products. Regarding eye monitoring experiments, the BeGaze production product offers sophisticated software packages for analysis of recorded eye-tracking data. The data gathered via eye-tracking were analysed by quantitative methods measuring the gaze and eye activities. The software does the collection of data and provides advanced tools for analysing the collected data. This includes tools for defining Area of Interests (AOIs) and running statistical calculations on AOIs. Furthermore, the visualization of eye-tracking data as heat maps was provided.

\section{FINDINGS AND DISCUSSION}

\section{Amplitudes and latencies of the P300 ERP component}

An independent sample t-test was conducted to compare consumers' decision making of marketing mix elements in green product and non-green product conditions.

At P300 amplitude for F4 electrode of price element (Table 1), there was a significant difference in the score for green product $(1.64 \pm 1.25)$ and non-green product $(0.99 \pm 0.65)$ condition; $t(42)=2.18, p=0.03$. These results suggest that a green product does have an effect on consumers' decision making based on price. Specifically, the results suggest that when consumers choose a green product, it depends on the price of the product.

Table 1. An independent sample t-test for amplitudes of P300 ERP component

\begin{tabular}{|c|c|c|c|}
\hline Sites & $\begin{array}{c}\text { Green Product } \\
(\text { mean } \pm \text { SD })\end{array}$ & $\begin{array}{c}\text { Non-green Product } \\
(\text { mean } \pm \text { SD })\end{array}$ & P-Value \\
\hline \multicolumn{4}{|l|}{ Product } \\
\hline F3 & $3.38 \pm 3.35$ & $2.66 \pm 2.41$ & 0.42 \\
\hline $\mathrm{F} 4$ & $1.30 \pm 0.85$ & $1.23 \pm 0.95$ & 0.78 \\
\hline $\mathrm{T} 3$ & $1.59 \pm 1.60$ & $1.43 \pm 1.51$ & 0.74 \\
\hline $\mathrm{T} 4$ & $1.33 \pm 1.54$ & $1.01 \pm 0.86$ & 0.40 \\
\hline $\mathrm{O} 1$ & $1.11 \pm 1.20$ & $1.51 \pm 1.63$ & 0.36 \\
\hline $\mathrm{O} 2$ & $1.02 \pm 1.11$ & $1.30 \pm 1.30$ & 0.44 \\
\hline $\mathrm{Fz}$ & $3.42 \pm 2.98$ & $4.11 \pm 6.81$ & 0.67 \\
\hline $\mathrm{Cz}$ & $1.19 \pm 1.29$ & $1.01 \pm 0.92$ & 0.59 \\
\hline $\mathrm{Pz}$ & $1.57 \pm 2.02$ & $1.57 \pm 2.36$ & 0.99 \\
\hline \multicolumn{4}{|l|}{ Price } \\
\hline F3 & $2.96 \pm 3.07$ & $3.11 \pm 3.95$ & 0.89 \\
\hline $\mathrm{F} 4$ & $1.64 \pm 1.25$ & $0.99 \pm 0.65$ & 0.03 \\
\hline $\mathrm{T} 3$ & $1.78 \pm 1.20$ & $1.18 \pm 0.71$ & 0.05 \\
\hline $\mathrm{T} 4$ & $1.58 \pm 1.18$ & $1.09 \pm 0.92$ & 0.13 \\
\hline $\mathrm{O} 1$ & $1.68 \pm 2.31$ & $1.15 \pm 1.14$ & 0.35 \\
\hline $\mathrm{O} 2$ & $1.80 \pm 3.05$ & $1.41 \pm 1.08$ & 0.57 \\
\hline $\mathrm{Fz}$ & $2.76 \pm 3.61$ & $4.18 \pm 4.57$ & 0.26 \\
\hline
\end{tabular}




\begin{tabular}{|c|c|c|c|}
\hline $\mathrm{Cz}$ & $1.81 \pm 2.26$ & $1.26 \pm 1.00$ & 0.30 \\
\hline $\mathrm{Pz}$ & $3.27 \pm 6.96$ & $1.47 \pm 1.54$ & 0.24 \\
\hline \multicolumn{4}{|c|}{ Place } \\
\hline F3 & $2.25 \pm 2.25$ & $1.92 \pm 2.49$ & 0.65 \\
\hline $\mathrm{F} 4$ & $3.63 \pm 2.97$ & $2.79 \pm 2.10$ & 0.29 \\
\hline $\mathrm{T} 3$ & $1.88 \pm 1.86$ & $1.95 \pm 1.35$ & 0.88 \\
\hline $\mathrm{T} 4$ & $2.05 \pm 1.35$ & $2.09 \pm 1.20$ & 0.91 \\
\hline $\mathrm{O} 1$ & $1.62 \pm 1.19$ & $1.81 \pm 1.16$ & 0.60 \\
\hline $\mathrm{O} 2$ & $1.51 \pm 1.20$ & $2.03 \pm 2.88$ & 0.45 \\
\hline $\mathrm{Fz}$ & $4.24 \pm 6.51$ & $4.54 \pm 5.53$ & 0.87 \\
\hline $\mathrm{Cz}$ & $2.33 \pm 2.26$ & $1.59 \pm 1.00$ & 0.17 \\
\hline $\mathrm{Pz}$ & $2.88 \pm 4.25$ & $2.28 \pm 2.58$ & 0.58 \\
\hline \multicolumn{4}{|c|}{ Promotion } \\
\hline F3 & $1.52 \pm 1.47$ & $2.26 \pm 2.44$ & 0.23 \\
\hline $\mathrm{F} 4$ & $1.71 \pm 2.28$ & $2.14 \pm 1.80$ & 0.49 \\
\hline $\mathrm{T} 3$ & $1.89 \pm 1.67$ & $1.51 \pm 0.99$ & 0.36 \\
\hline $\mathrm{T} 4$ & $1.06 \pm 0.96$ & $1.74 \pm 1.49$ & 0.08 \\
\hline $\mathrm{O} 1$ & $1.58 \pm 1.43$ & $1.52 \pm 1.21$ & 0.89 \\
\hline $\mathrm{O} 2$ & $1.32 \pm 1.61$ & $2.18 \pm 2.21$ & 0.15 \\
\hline $\mathrm{Fz}$ & $3.31 \pm 2.51$ & $3.70 \pm 5.41$ & 0.76 \\
\hline $\mathrm{Cz}$ & $1.52 \pm 1.07$ & $1.33 \pm 1.24$ & 0.59 \\
\hline $\mathrm{Pz}$ & $2.22 \pm 3.05$ & $1.82 \pm 1.74$ & 0.60 \\
\hline
\end{tabular}

At P300 latencies for Fz electrode of product element (Table 2), there was a significant difference in the score for green product $(462.40 \pm 37.44)$ and non-green product $(429.00 \pm 42.61)$ condition; $\mathrm{t}(42)=2.76, \mathrm{p}=0.01$. These results suggest that a green product does have an effect on consumers' decision-making based on the product. Specifically, the results suggest that when consumers choose a green product, they take into account the type of the product. At P300 latencies for $\mathrm{F} 3$ electrode of price element (Table 3.2), there was a significant difference in the score for green product $(438.10 \pm 33.26)$ and non-green product $(460.20 \pm 27.60)$ condition; $t(42)=2.40, p=0.02$. These results suggest that non-green product does have an effect on consumers' decision-making based on price. Specifically, the results suggest that when consumers buy a non-green product, they rely on the price of the product.

At P300 latencies for F4 electrode of promotion element (Table 2), there was a significant difference in the score for green product $(435.5 \pm 37.00)$ and non-green product $(461.10 \pm 29.84)$ condition; $t(42)=2.53, p=0.02$. These results suggest that non-green product does have an effect on consumers' decision making based on the promotion. Specifically, the results suggest that when consumers choose a non-green product, they look at the promotion of the product.

Table 2. An independent sample t-test for latencies of P300 ERP component

\begin{tabular}{|c|c|c|c|}
\hline Sites & Non-green Product & Green Product & $\mathrm{p}$-Value \\
\hline \multicolumn{4}{|l|}{ Product } \\
\hline F3 & $459.60 \pm 42.56$ & $445.60 \pm 39.37$ & 0.26 \\
\hline $\mathrm{F} 4$ & $438.00 \pm 43.19$ & $424.80 \pm 40.62$ & 0.30 \\
\hline $\mathrm{T} 3$ & $455.00 \pm 40.41$ & $441.90 \pm 41.71$ & 0.29 \\
\hline $\mathrm{T} 4$ & $415.00 \pm 43.86$ & $425.10 \pm 45.79$ & 0.46 \\
\hline $\mathrm{O} 1$ & $403.00 \pm 33.08$ & $403.00 \pm 31.22$ & $>0.99$ \\
\hline $\mathrm{O} 2$ & $395.90 \pm 26.49$ & $407.40 \pm 34.52$ & 0.22 \\
\hline $\mathrm{Fz}$ & $462.40 \pm 37.44$ & $429.00 \pm 42.61$ & 0.01 \\
\hline $\mathrm{Cz}$ & $418.20 \pm 31.41$ & $415.70 \pm 31.32$ & 0.80 \\
\hline $\mathrm{Pz}$ & $405.50 \pm 34.54$ & $406.90 \pm 38.22$ & 0.90 \\
\hline \multicolumn{4}{|l|}{ Price } \\
\hline F3 & $438.10 \pm 33.26$ & $460.20 \pm 27.60$ & 0.02 \\
\hline $\mathrm{F} 4$ & $457.80 \pm 37.62$ & $457.20 \pm 36.22$ & 0.96 \\
\hline T3 & $442.00 \pm 29.42$ & $436.50 \pm 36.52$ & 0.59 \\
\hline $\mathrm{T} 4$ & $435.50 \pm 52.26$ & $418.40 \pm 45.49$ & 0.25 \\
\hline $\mathrm{O} 1$ & $400.20 \pm 36.70$ & $400.20 \pm 37.32$ & $>0.99$ \\
\hline $\mathrm{O} 2$ & $408.00 \pm 37.54$ & $395.00 \pm 26.08$ & 0.19 \\
\hline $\mathrm{Fz}$ & $453.50 \pm 33.95$ & $454.70 \pm 32.25$ & 0.91 \\
\hline $\mathrm{Cz}$ & $434.00 \pm 28.32$ & $425.20 \pm 36.32$ & 0.38 \\
\hline $\mathrm{Pz}$ & $407.20 \pm 39.69$ & $400.90 \pm 22.82$ & 0.52 \\
\hline \multicolumn{4}{|l|}{ Place } \\
\hline F3 & $433.60 \pm 45.54$ & $446.60 \pm 41.70$ & 0.33 \\
\hline
\end{tabular}




\begin{tabular}{cccc} 
F4 & $455.00 \pm 29.95$ & $454.10 \pm 29.53$ & 0.92 \\
T3 & $409.30 \pm 37.69$ & $425.60 \pm 45.16$ & 0.20 \\
T4 & $427.50 \pm 37.54$ & $436.40 \pm 46.53$ & 0.49 \\
O1 & $403.80 \pm 38.88$ & $400.30 \pm 39.27$ & 0.77 \\
O2 & $403.90 \pm 35.33$ & $398.00 \pm 31.82$ & 0.56 \\
Fz & $454.00 \pm 35.16$ & $461.70 \pm 26.52$ & 0.41 \\
Cz & $426.90 \pm 33.93$ & $421.60 \pm 35.17$ & 0.61 \\
Pz & $408.30 \pm 38.29$ & $405.5 \pm 35.51$ & 0.80 \\
\hline Promotion & $446.50 \pm 38.94$ & $451.70 \pm 44.21$ & 0.68 \\
F3 & $435.5 \pm 37.00$ & $461.10 \pm 29.84$ & 0.02 \\
F4 & $437.00 \pm 39.67$ & $419.60 \pm 43.38$ & 0.17 \\
T3 & $418.00 \pm 38.79$ & $435.90 \pm 37.42$ & 0.13 \\
T1 & $410.10 \pm 35.88$ & $413.60 \pm 32.99$ & 0.74 \\
O2 & $402.70 \pm 34.21$ & $406.40 \pm 37.60$ & 0.73 \\
Fz & $446.80 \pm 41.15$ & $461.10 \pm 32.89$ & 0.21 \\
Cz & $426.10 \pm 33.05$ & $441.10 \pm 36.78$ & 0.16 \\
Pz & $420.30 \pm 46.48$ & $411.00 \pm 34.73$ & 0.45 \\
\hline
\end{tabular}

Significant if $\mathrm{p}$-Value $\leq 0.05$

Attention map of eye-tracking (ET)

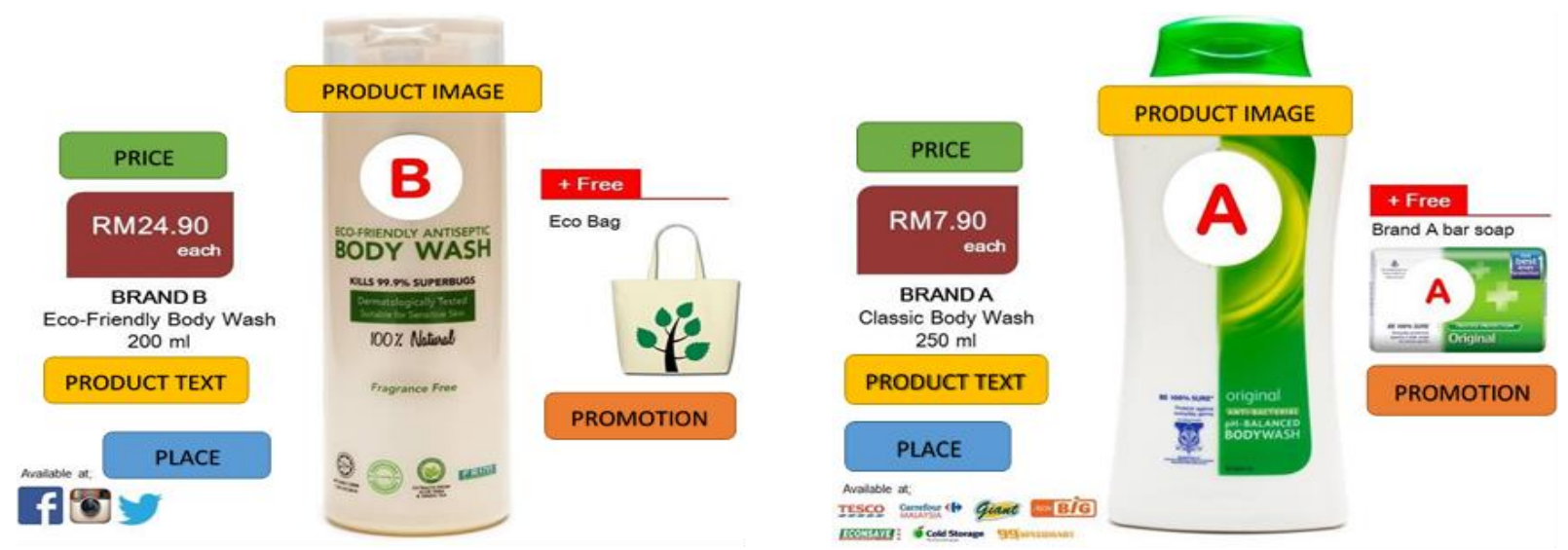

Green Product

Non-green Product

Figure 3. Group of Area of Interest (AOI) for green and non-green product

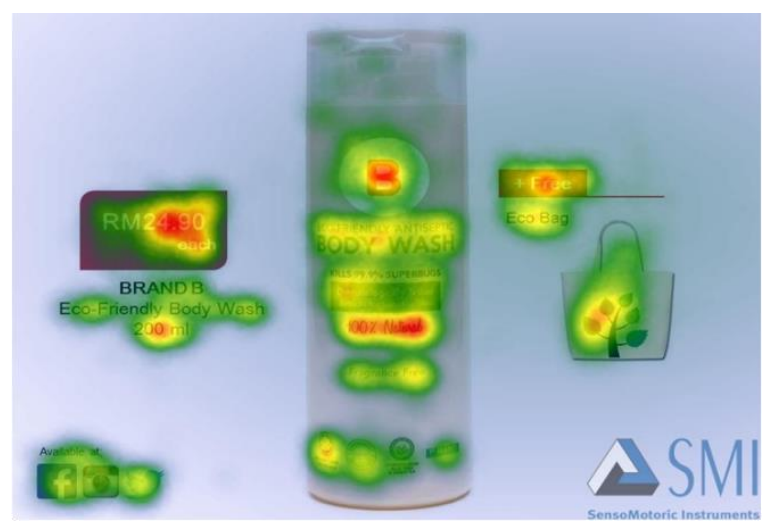

Green Product

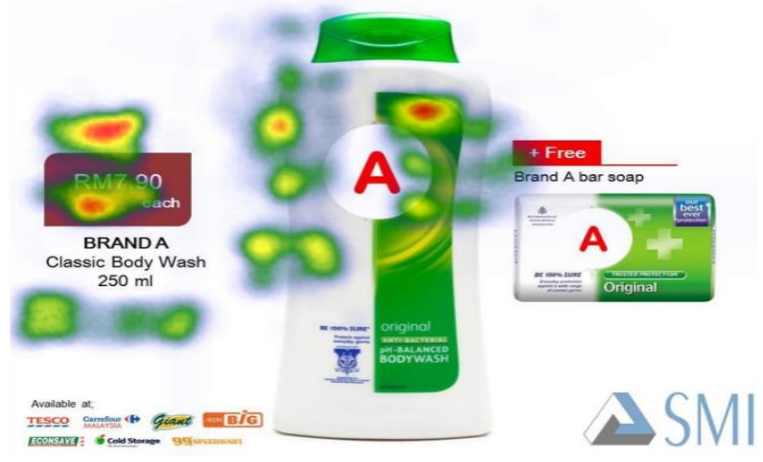

Non-green Product

Figure 4. Heat map of green and non-green product

Figure 4 presents the heat map visualized by the SMI Eye tracker and shows the average fixation duration and gaze locations of respondents, that measure Area of Interest (AOI) as shown in Figure 3. Table 3 shows the duration of average fixation lasts for respondents to focus on green and non-green products during visualization of stimuli. The highest average fixation time for the green product was on the price element, while for the non-green product was on the product image element. The lowest average fixation time for both green and non-green products was on place element. Figure 5 illustrates eye fixation position from highest to lowest rank on marketing elements of the green and non-green product. 
Table 3. Average fixation AOI for green and non-green product

\begin{tabular}{ccc}
\hline & \multicolumn{2}{c}{ Average Fixation (ms) } \\
\cline { 2 - 3 } Marketing Elements & Green Product & Non-green Product \\
\hline Product Image & 438.9 & 460.1 \\
Product Text & 403.1 & 389.8 \\
Price & 447.0 & 426.1 \\
Place & 311.2 & 326.9 \\
Promotion & 440.1 & 443.9
\end{tabular}

\begin{tabular}{|c|c|c|}
\hline Green Product & & High \\
Price & & Non-green Product \\
Promotion & & $\begin{array}{c}\text { Product Image } \\
\text { Promotion } \\
\text { Product Image } \\
\text { Product Text } \\
\text { Place }\end{array}$ \\
& & $\begin{array}{c}\text { Price } \\
\text { Product Text } \\
\text { Place }\end{array}$ \\
\hline
\end{tabular}

Figure 5. Eye fixation position from highest to lowest rank marketing elements of the green and non-green product

The main findings of this study were about the cognitive response and gaze behaviour during different displays of products (green and non-green) which contribute important information that influence customers' decision-making. Cognitive response and gaze behaviour were investigated using the ERP and the Eye Tracking procedures, respectively. In this study, the marketing mix element settings of interest were product, price, place, and promotion. The cognitive function and working memory were shown by the P300 ERP component (Polich, 2003). The amplitude of the P300 component is determined by the attention, stimulus probability, and attention allocation. Greater attention shows a higher amplitude of the P300 component (Sur \& Sinha, 2009). This study found that the higher amplitude of the P300 component at the F4 electrode for the price element was obvious on the green product compared to the non-green product. This result proved that subjects had additional visual cognitive processing in decision-making to buy the green product and selected the green product view during subconscious attentive processing.

Meanwhile, the latency of the P300 component was reported due to the complexity of stimuli, the effectiveness of selection, and continuous attention. Lin, Cross, Jones, and Childers (2018) mentioned longer P300 latency indicates less attention. Latency also increases when targets are more difficult to distinguish from non-target (Linden, 2005). The increase in P300 latency is linked to the difficulty in the processing of cognitive information. This study found that there is 3 significant result for the latency. The first latency was shown at the Fz electrode for the product element. This result showed that green product has longer latency compared to the non-green product. The finding from this study is supported by Pickett-Baker and Ozaki (2008), in which there is limited awareness about green products even though consumers are willing to purchase green products. This finding is also supported by Khare, Mukerjee, and Goyal (2013) who mentioned that there is a lack of awareness regarding green products. The majority of respondents who claimed to be aware of green products did not know as to what green products represent (Kumar, Garg \& Makkar, 2012). The second latency was found at the F3 electrode for the price element. This finding showed that the green product has a shorter latency compared to the non-green product. Another finding indicated that price is an important element when deciding to buy green products. This is because not all consumers are willing to pay a higher price for green products (Barbarossa $\&$ Pastore, 2015). This is also because consumers are very sensitive to price changes and it easily affects consumers' purchasing decisions. The third latency was found at the F4 electrode for the promotion element. This finding showed that the green product has a shorter latency compared to the non-green product. According to the analysis of results by Boztepe (2012), environmental awareness, green product features, green promotion activities, and green price affect the green purchasing behaviours of the consumers in a positive way. Successful promotion is a key element for a successful marketing strategy. The overall result indicated that all significant results were found in the frontal area. Decision making takes place at the frontal lobes (Collins \& Koechlin, 2012). The area is more relevant to the decision-making process.

Heat maps can illustrate visual attention by showing the fixation of locations and fixation times in the stimuli across regions (Duchowski, 2003). The heat map explains the focusing duration on the screen by using colour representation (Ramakrisnan, Jaafar, Razak, \& Ramba, 2012). These coloured hotspots, green and red, show varying attention. Red is the highest fixation level, followed by yellow and green, and no fixation is possible in areas without colour (Luan et al., 2016). Eye fixations and their duration tend to be associated with parts of the image preferred by the respondent. The evidence mentioned that longer eye fixation or gaze involves higher attention and interest (Matukin, Ohme \& Boshoff, 2016). Longer fixation times and a higher number of fixations increase positive attitudes towards a brand (Chiu, Lo \& 
Hsieh, 2017). This is because objects with longer fixations have a higher probability of being chosen (Slanzi, Balazs \& Velásquez, 2017). These results showed that stimuli attracting more fixations are more frequently considered desirable by respondents (Bebko, Sciulli \& Bhagat, 2014). Eye-tracking metrics provide sufficient evidence to support the claim that the price of green products plays a large role in consumers' reaction and decision making.

Guiding consumers' actions in visual information are important. Thus, this study applied the eye-tracking method that focused on Area of Interest (AOI) and fixation of the consumers' eye movement in order to obtain the results. The finding showed that the product image of non-green products got higher attention from the consumers compared to the other elements. This is supported by Hutton and Nolte (2011) that stated consumers in their earlier study looked more at pictures of ads and less at text content to consider buying the products. This finding showed that fixation can be powerful stimuli in attention orientation. Eye-tracking can identify which parts of the marketing mix elements are focused on by the consumers and which parts are ignored. The results revealed that the highest elements that catch the attention of the consumers are product image (for non-green) and price (for green) products. Based on the observation, the price of green products gets higher attention due to the amount that respondents need to pay compared to the non-green products. This is because the price is the key to decision making. The price for green products is usually slightly higher, due to the following reasons which are low production level, time-consuming, and high certification costs. When respondents have a longer fixation on the element, this also increases product confidence and encourages consumers to think about the quality of their decisions (Santos et al., 2015). This situation happens also due to the price areas that gather more visual fixations, because the colours are more intense, and attract attention from the respondents. Price elements are also the most important attributes for consumers.

However, the lowest element which is Place (green and non-green), received less attention from the respondents. Place is where the respondents are looking for the product to purchase. In the study, Place varies from the concept store to online shops. The results indicated that Place is not important for respondents to purchase the products since it is available almost everywhere and available online. Therefore, the benefits of eye-tracking allow seeing how consumers respond in real-time to various marketing messages and understand their cognitive responses. The findings also help marketers and researchers to gather objective and unbiased information below the consciousness level of consumers. Eye-tracking techniques have enabled the identification of specific product elements that have contributed to greater consumer attention (Blum, 2016).

\section{CONCLUSION}

While previous research on the topic generally examined green consumption related to a single product label, numerous questions exist about why consumers choose various green products and services. This current research addressed these concerns by examining individuals' actual green consumption as it relates to their subconscious mind and personal effect towards the marketing mix on green and non-green products. In this view, this study looked at the growing field of neuromarketing and aimed to explore consumers' subconscious minds by examining the effectiveness of the marketing mix on consumers' decision-making process.

The main findings of this study were about the cognitive response and gaze behaviour during different displays of products (green and non-green) which contribute important information that influence customers' decision making. Cognitive response and gaze behaviour were investigated using the ERP and the Eye Tracking procedures, respectively. Therefore, the benefits of eye-tracking allow seeing how consumers respond in real-time to various marketing messages and understand their cognitive responses. The findings also help marketers and researchers to gather objective and unbiased information below the consciousness level of consumers. Eye-tracking techniques have enabled the identification of specific product elements that have contributed to greater consumer attention (Blum, 2016).

This study supported the finding and discovered that the marketing mix elements do deliver impact on decision making. Based on the results of the study, it can help marketing managers to plan appropriate marketing strategies for marketing mix elements to meet their possible target and profit. In order to govern green purchasing behaviour, the price must be normal, hence making it easier to make sustainable choices. Focusing more on the promotional elements of the marketing mix will help marketers to reach their customers. Moreover, neuromarketing can identify any subconscious movements that are not accessible to the traditional research method. This evidence offers a new marketing opportunity for marketers to improvise their marketing strategy and increase sales growth. This concludes that the simple yet basic marketing strategy concept becomes better with the neuromarketing approach. The research shows that individuals' total green consumption is related to their environmental knowledge and personal effect on the environment. These findings have important implications for policymakers and businesses alike as greater efforts are made to encourage more widespread green consumption. When green products are successfully communicated to the consumer, it may arouse consumer emotions, such as protective feelings toward the environment (Lin \& Huang, 2012). Once businesses remove the obstacles between consumers' desire to buy green and the actual follow-through of those sentiments, green products could experience explosive sales growth. The better a company's green marketing mix, the more consumer it can attract. Thus, building a strong neuromarketing strategy incorporation can do much more to cultivate green consumers. The green marketing mix is advanced to help in guiding future research.

\section{REFERENCES}

Aaker, D. A. (1996). Measuring brand equity across products and markets. California Management Review, 38(3), $102-120$. 
Abdul Wahid, N., Rahbar, E., \& Tan S. S. (2011). Factors Influencing the Green Purchase Behavior of Penang Environmental Volunteers. International Business Management, 5(1), 38-49.

Agarwal, S., \& Dutta, T. (2015). Neuromarketing and consumer neuroscience: Current understanding and the way forward. Decision, 42(4), 457-462.

Banyte,J., Brazioniene, L. \& Gadeikiene, A. (2010). Expression of Green Marketing Developing the Conception of Corporate Social Responsibility. Inzinerine Ekonomika-Engineering Economics, 21(5), 550-560.

Barbarossa, C., \& Pastore, A. (2015). Why environmentally conscious consumers do not purchase green products. Qualitative Market Research: An International Journal, 18(2), 188-209.

Bebko, C., Sciulli, L. M., \& Bhagat, P. (2014). Using Eye Tracking to Assess the Impact of Advertising Appeals on Donor Behavior. Journal of Nonprofit \& Public Sector Marketing, 26(4), 354-371.

Blum, B. (2016). Consumer Neuroscience: A Multi-Disciplinary Approach to Marketing Leveraging Advances in Neuroscience, Psychology and Economics. Claremont McKenna College.

Boztepe, A. (2012). Green Marketing and Its Impact on Consumer Buying Behavior. European Journal of Economic and Political Studies, 5(1), 5-21.

Chiu, Y. P., Lo, S. K., \& Hsieh, A. Y. (2017). How colour similarity can make banner advertising effective: insights from Gestalt theory. Behaviour and Information Technology, 36(6), 606-619.

Colaferro, C. A., \& Crescitelli, E. (2014). The Contribution of Neuromarketing to the Study of Consumer Behavior. Brazilian Business Review, 11(3), 123-143.

Collins A. \& Koechlin E. (2012) Reasoning, Learning, and Creativity: Frontal Lobe Function and Human Decision-Making. PLoS Biol 10(3), e1001293.

Do Paço, A., Alves, H., Shiel, C., \& Filho, W. L. (2013). Development of a green consumer behaviour model. International Journal of Consumer Studies, 37(4), 414-421.

Duchowski, A.T. (2003). Eye Tracking Methodology: Theory and Practice. Springer

Gan, C., Wee, H. Y., Ozanne, L., \& Kao, T.-H. (2008). Consumers' purchasing behavior towards green products in New Zealand. Innovative Marketing, 4(1), 93-102.

Hammou, K. A., Galib, M. H., \& Melloul, J. (2013). The Contributions of Neuromarketing in Marketing Research. Journal of Management Research, 5(4), 20-30.

Heding, T., Knudtzen, C.F. \& Bjerre, M., 2009. Brand Management - Research, theory and practice, New York.

Huang, Y. \& Kuo, F., 2011. An eye-tracking investigation of internet consumers' decision deliberateness. Internet Research, 21(5), $541-561$.

Hutton, S. B., \& Nolte, S. (2011). The effect of gaze cues on attention to print advertisements. Applied Cognitive Psychology, 25(6), $887-892$.

Isa, S.M, L Kelly and Kiumarsi, S. (2020). Brand switching through marketing mix: the role of brand effect on smartphone users. International Journal Process Management and Benchmarking, 10(3), 419-428.

Luan, J., Yao, Z., Zhao, F.T \& Liu, H. (2016). Search product and experience product online reviews: An eyetracking study on consumers' review search behavior. Computers in Human Behavior, 65, 420-430.

Khare, A., Mukerjee, S., \& Goyal, T. (2013). Social influence and green marketing: An exploratory study on Indian consumers. Journal of Customer Behaviour, 12(4), 361-381.

Khan, M. T. (2014). The Concept of "Marketing Mix" and its Elements: A Conceptual Review Paper. International Journal of Information, Business and Management, 6(2), 95-107.

Kolar, E. (2014). Neuromarketing and Marketing Management: Contributions of Neuroscience for the traditional Marketing Mix. University of Twente.

Kumar, S., Garg, R., \& Makkar, A. (2012). Consumer Awareness and Perception Towards Green Products: A Study of Youngsters in India. International Journal of Marketing \& Business Communication, 1(4), 35-43.

Lee, N., Broderick, A. J., \& Chamberlain, L. (2007). What is "neuromarketing"? A discussion and agenda for future research. International Journal of Psychophysiology, 63(July 2004), 199-204.

Lin, P. C., \& Huang, Y. H. (2012). The influence factors on choice behavior regarding green products based on the theory of consumption values. Journal of Cleaner Production, 22(1), 11-18.

Lin, M. H., Cross, S. N. N., Jones, W. J., \& Childers, T. L. (2018). Applying EEG in consumer neuroscience. European Journal of Marketing, 52(1-2), 66-91.

Linden, D. E. J. (2005). The P300: where in the brain is it produced and what does it tell us? The Neuroscientist, 11(6), 563-576.

Mansor, A.A \& Isa, S.M. (2018). The Impact of Eye Tracking on Neuromarketing for Genuine Value-Added Applications. Global Business and Management Research: An International Journal, 10(1), (Special Issue).

Matukin, M., R. Ohme, and C. Boshoff. 2016. Toward a better understanding of advertising stimuli processing: Exploring the link between consumers' eye fixation and their subconscious responses. Journal of Advertising Research 56(2), 205-216.

McDowell, W. S., \& Dick, S. J. (2013). The marketing of neuromarketing: Brand differentiation strategies employed by prominent neuromarketing firms to attract media clients. Journal of Media Business Studies, 10(1), 25-40.

Pickett-Baker, J., \& Ozaki, R. (2008). Pro-environmental products: marketing influence on consumer purchase decision. Journal of Consumer Marketing, 25(5), 281-293.

Polich, J. (2003). Detection of change: Event-related potential and fMRI finding. Kluwer academic publishers, Dordrecht.

Ramakrisnan, P., Jaafar, A., Razak, F. H. A., \& Ramba, D. A. (2012). Evaluation of user Interface Design for Leaning Management System (LMS): Investigating Student's Eye Tracking Pattern and Experiences. Procedia - Social and Behavioral Sciences, 67 , 527-537.

Sadedil, S., Bozkurt, I., Uraltas, K., \& Tas, C. (2016). Comparison of Conventional Marketing Researches and Neuromarketing Researches in Regard to the Efficiency of Marketing Messages, The Journal of Neurobehavioral Sciences, 3(3), 101-109.

Santos, R. D. O. J. Dos, Oliveira, J. H. C. De, Rocha, J. B., \& Giraldi, J. D. M. E. (2015). Eye Tracking in Neuromarketing: A Research Agenda for Marketing Studies. International Journal of Psychological Studies, 7(1), 32-42. 
Slanzi, G., Balazs, J. A., \& Velásquez, J. D. (2017). Combining eye tracking, pupil dilation and EEG analysis for predicting web users click intention. Information Fusion, 35, 51-57.

Sowndhararajan, K., Kim, M., Deepa, P., Park, S. J., \& Kim, S. (2018). Application of the p300 event-related potential in the diagnosis of epilepsy disorder: A review. Scientia Pharmaceutica, 86(2), 2-13.

Suki, N.M (2013). Green Products Purchases: Structural Relationships of Consumers' Perception of Eco-Label, Eco-Brand And Environmental Advertisement, Journal of Sustainability Science and Management, 8(1), 1-10.

Sur, S. \& Sinha, V. (2009). Event-related potential: An overview. Industrial Psychiatry Journal. 18(1), 70-73.

Wang, L., Zheng, J., Huang, S., \& Sun, H. (2015). P300 and Decision Making under Risk and Ambiguity. Computational Intelligence and Neuroscience, 2015, 13-15.

Ying-Ching, L. \& Chang, C.A. (2012). Double Standard: The Role of Environmental Consciousness in Green Product Usage. Journal of Marketing, 2012, 76(5), 125-134.

\section{ACKNOWLEDGEMENT}

This study was supported by the RUI grant (1001/PPAMC/8016038) Universiti Sains Malaysia (USM).

\section{AUTHORS' BIOGRAPHY}

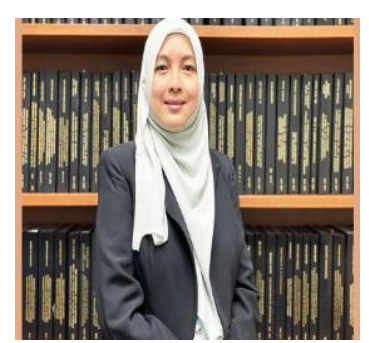

Salmi teaches Master Business Administration (MBA) and Master of Cognitive Neurosciences programmes and specialises in research on marketing. Having worked for past years on the R\&D organisation, recently she has been research on marketing surrounding neuromarketing, tourism marketing, marketing innovation, branding and Corporate Social Responsibility (CSR). 